\title{
Cigarro Eletrônico e Doenças Cardiovasculares
}

doi: https://doi.org/10.32635/2176-9745.RBC.2019v65n3.542

\author{
Eletronic Cigarette and Cardiovascular Disease \\ Cigarrillo Electronico y Enfermedad Cardiovascular
}

\author{
Jaqueline Ribeiro Scholz'; Tania Ogawa Abe ${ }^{2}$
}

\section{INTRODUÇÃO}

O cigarro eletrônico começou a ser usado nos Estados Unidos (EUA) e na Europa entre 2006 e $2007^{1}$ e, desde entáo, sua disseminação é crescente e novos produtos são lançados sucessivamente no mercado. A popularidade dos cigarros eletrônicos vem crescendo exponencialmente entre adolescentes dos EUA. Entre 2011 e 2018, houve um aumento de cerca de 13 vezes no consumo entre os jovens, passando de $1,5 \%$ para $20,8 \%^{2}$. No início, o design do cigarro eletrônico lembrava o de um cigarro convencional, mas divulga-se amplamente que é um produto sem combustão para liberação de nicotina, tentando já implicar o conceito de ser mais seguro que o convencional. Com o passar dos anos, esses dispositivos se tornaram mais robustos, com maior capacidade de armazenamento e mais vaporização, com maior capacidade e liberação de nicotina, disseminando cada vez mais o consumo, na medida em que se aproximava do cigarro convencional no quesito satisfação do fumante em obter nicotina ${ }^{1}$. Em 2017, surgiu o JUUL ${ }^{\circledR}$, cigarro eletrônico com formato de "mod-pods", pequeno, semelhante ao dispositivo USB, fácil de ser transportado e escondido, com inúmeras opçôes de sabores, e com capacidade de liberação de nicotina em alta concentração, tornando rapidamente seus usuários adictos ao produto. Sua ampla divulgação na Internet atraiu adolescentes e jovens à experimentação (novos usuários), e hoje já é o cigarro eletrônico mais consumido entre os jovens americanos. Para os fumantes, esses novos produtos foram propagados inicialmente como se fossem uma "alternativa mais segura" em relação ao cigarro convencional, fato jamais comprovado ${ }^{1}$. Até porque a cessação do tabagismo é entendida como interrupção total do consumo regular de qualquer produto que contenha nicotina, seja cigarro eletrônico ou convencional.
Os fabricantes dos cigarros eletrônicos são, hoje, os mesmos do cigarro convencional, e insistem em propagar que seus produtos são mais seguros que os cigarros convencionais, fundamentados no argumento de que o eletrônico tem menos substâncias tóxicas do que o convencional. Para isso, utilizam estudos científicos que comparam quantidade de substâncias presentes nos cigarros convencionais versus a quantidade presente nos cigarros eletrônicos. Fato grave a destacar é que uma recente revisão sistemática da literatura mostrou que estudos financiados pela indústria do tabaco apresentam uma chance muito maior de demonstrar resultados positivos (em favor do cigarro eletrônico, com menos efeitos adversos relacionados a seu uso) do que estudos não financiados, ou cujos autores não possuam conflito financeiro com a indústria do cigarro ${ }^{3}$. Segundo esse estudo, 95\% das pesquisas com cigarros eletrônicos não financiados pela indústria relataram algum efeito ou substância maléfica no cigarro eletrônico, enquanto somente $39 \%$ dos estudos financiados alardearam sobre riscos relacionados ao uso de cigarro eletrônico. A presença de conflito de interesses moderado a forte foi associada com $91,5 \%$ de chance de não encontrar nenhum alarme quanto ao uso de cigarro eletrônico.

\section{DESENVOLVIMENTO}

Está bem estabelecido na literatura que o cigarro convencional causa inúmeros malefícios à saúde. $\mathrm{O}$ tabagismo é a principal causa de morte evitável no mundo e, entre as doenças causadas pelo tabagismo, destacam-se as doenças cardiovasculares, como infarto agudo do miocárdio, acidente vascular cerebral, e doenças vasculares periféricas. O tabagismo compromete a funçáo endotelial e aumenta a liberação de radicais livres de oxigênio, além de

${ }^{1}$ Programa de tratamento do Tabagismo do Instituto do Coração do Hospital das Clínicas da Faculdade de Medicina da Universidade de São Paulo (InCor/HC/FMUSP). São Paulo (SP), Brasil. Orcid iD: https://orcid.org/0000-0002-4139-8516

${ }^{2}$ Programa de Tratamento do Tabagismo do InCor/HC/FMUSP. São Paulo (SP), Brasil. Orcid iD: https://orcid.org/0000-0001-6757-1455

Endereço para correspondência: Jaqueline R Scholz. Avenida Dr. Eneas de Carvalho Aguiar, 44 - $1^{\circ}$ andar - Bloco 2 - Cerqueira César. São Paulo (SP), Brasil. CEP 05403-904. E-mail jaquelineincor@yahoo.com.br 
acelerar o processo aterosclerótico, mesmo em indivíduos com baixo consumo de cigarros e em tabagistas passivos ${ }^{4-6}$.

Os malefícios causados pelo cigarro eletrônico são menos conhecidos, uma vez que são dispositivos que estâo em constante desenvolvimento e mudança e, em razão do curto tempo em que estão no mercado, não é possível determinar os malefícios do uso em longo prazo, sem contar que existem muitos usuários que usam cigarros convencional e eletrônico concomitantemente. $\mathrm{O}$ cigarro eletrônico não expôe o usuário ao monóxido de carbono, uma vez que não há combustão; no entanto, elementos como a nicotina, que é sabidamente causadora de efeitos maléficos ao sistema cardiovascular, estão presentes. Outros produtos químicos que são inalados pelo fumante de cigarro eletrônico variam de acordo com a marca do cigarro e com o "e-líquido" utilizado; mas, entre os componentes, destacam-se solventes químicos, compostos orgânicos voláteis e aldeídos, metais pesados, hidrocarbonetos aromáticos policíclicos, material particulado ultrafino, além de compostos que produzem os sabores ${ }^{7-8}$. Portanto, cigarros eletrônicos causam aumento de estresse oxidativo e liberaçáo de mediadores inflamatórios ${ }^{9-10} \mathrm{e}$ alteração na função endotelial, levando a um aumento no risco de doenças cardiovasculares.

Estudo recente conduzido por Bhatta et $\mathrm{a}^{11}$. concluiu que tanto o consumo ocasional como o consumo diário de cigarro eletrônico estáo associados com aumento no risco de infarto agudo do miocárdio, mesmo após ajuste para o consumo concomitante de cigarro convencional (OR 2,25 - consumo diário; OR 1,99 - consumo ocasional). $\mathrm{O}$ uso de cigarro eletrônico teve um efeito semelhante ao uso do cigarro convencional no risco de infarto do miocárdio. Nesse mesmo estudo, o uso combinado de cigarro convencional e eletrônico teve um desfecho pior do que o uso isolado de uma das formas $(\mathrm{OR} 6,64)^{11}$. Outro estudo de Alzahrani et al. ${ }^{12}$ já havia demonstrado que o consumo diário de cigarro eletrônico está associado a aumento de risco de infarto (OR 1,79).

Lee et al. ${ }^{13}$, por sua vez, avaliaram o impacto dos principais componentes de cigarros eletrônicos consumidos nos EUA na função e integridade endotelial, na resposta inflamatória, no resultado da interação entre células endoteliais e macrófagos. Essas alteraçôes fazem parte da fisiopatologia das doenças cardiovasculares fatais e não fatais. Nesse estudo, os autores avaliaram o efeito de e-líquidos de cigarros eletrônicos na viabilidade de células endoteliais derivadas de células-tronco pluripotentes humanas de indivíduos saudáveis, demonstrando um aumento na quantidade de $\mathrm{H}_{2} \mathrm{O}_{2}$ nas células-tronco, aumento de interleucinas e outras citocinas inflamatórias, após 48 horas de exposição, para a maioria dos e-líquidos testados ${ }^{13}$.

\section{CONCLUSÃO}

O cigarro eletrônico foi lançado no mercado como um possível redutor de danos à saúde e alardeado como uma possível terapêutica para a cessaçáo do tabagismo convencional. Estudos iniciais patrocinados pela indústria do cigarro corroboraram essas finalidades. Porém, com o desenvolvimento de novos estudos, não patrocinados, percebeu-se que o potencial de danos gerados pelo consumo de cigarro eletrônico é bem maior do que o inicialmente pensado e, em termos de cessação do tabagismo, tem ocorrido a troca (parcial ou total) do cigarro convencional pelo cigarro eletrônico, porém, o fumante continua a sofrer os efeitos maléficos do consumo de nicotina e outros compostos tóxicos do cigarros eletrônico, bem como gerar aerossol ao utilizar o cigarro eletrônico, criando a categoria de "tabagismo passivo de cigarro eletrônico", composto, sobretudo, de material particulado ultrafino.

Assim como para o cigarro convencional, não há um nível considerado seguro para o consumo de cigarro eletrônico - o seguro é não consumir.

\section{CONTRIBUIÇÕES}

Ambas as autoras participaram de todas as etapas do manuscrito e aprovação da versão final para publicação.

\section{DECLARAÇÃO DE CONFLITO DE INTERESSES}

Nada a declarar.

\section{FONTES DE FINANCIAMENTO}

Não há.

\section{REFERÊNCIAS}

1. Darville A, Hahn EJ. E-cigarettes and atherosclerotic cardiovascular disease: what clinicians and researchers need to know. Curr Atheroscler Rep. 2019;21(5):15. doi: https://doi.org/10.1007/s11883-019-0777-7

2. Cullen KA, Ambrose BK, Gentzke AS, et al. Notes from the field: use of electronic cigarettes and any tobacco product among middle and high school students United States, 2011-2018. MMWR Morb Mortal Wkly Rep. 2018;67(45):1276-77. doi: https://dx.doi. org/10.15585/mmwr.mm6745a5

3. Pisinger C, Godtfredsen N, Bender AM. A conflict of interest is strongly associated with tobacco industryfavourable results, indicating no harm of e-cigarettes. Prev Med. 2019;119:124-31. doi: https://doi.org/10.1016/j. ypmed.2018.12.011 
4. Glantz SA, Parmley WW. Passive smoking and heart disease: mechanisms and risk. JAMA. 1995;273(13):1047-53. https://doi.org/10.1001/ jama.1995.03520370089043

5. Howard G, Thun MJ. Why is environmental tobacco smoke more strongly associated with coronary heart disease than expected? A review of potential biases and experimental data. Environ Health Perspect. 1999;107(Suppl 6):853-8. doi: https://doi.org/10.1289/ ehp. 99107 s6853

6. Law MR, Wald NJ. Environmental tobacco smoke and ischemic heart disease. Prog Cardiovasc Dis. 2003;46(1):31-8. doi: https://doi.org/10.1016/S00330620(03)00078-1

7. Fuoco FC, Buonanno G, Stabile L, et al. Influential parameters on particle concentration and size distribution in the mainstream of e-cigarettes. Environ Pollut. 2014;184:523-29. doi: https://doi.org/10.1016/j. envpol.2013.10.010

8. Cheng T. Chemical evaluation of electronic cigarettes. Tob Control. 2014;23(Suppl 2):ii11-ii7. doi: https://doi. org/10.1136/tobaccocontrol-2013-051482

9. Carnevale R, Sciarretta S, Violi F, et al. Acute impact of tobacco vs electronic cigarette smoking on oxidative stress and vascular function. Chest. 2016;150(3):606-12. doi: https://doi.org/10.1016/j.chest.2016.04.012

10. Moheimani RS, Bhetraratana M, Yin F, et al. Increased cardiac sympathetic activity and oxidative stress in habitual electronic cigarette users: implications for cardiovascular risk. JAMA Cardiol. 2017;2(3):278-84. doi: https://doi.org/10.1001/jamacardio.2016.5303

11. Bhatta DN, Glantz SA. Electronic cigarette use and myocardial infarction among adults in the us population assessment of tobacco and health. J Am Heart Assoc. 2019;8(12):e012317. doi: https://doi.org/10.1161/ JAHA.119.012317

12. Alzahrani T, Pena I, Temesgen N, et al. Association between electronic cigarette use and myocardial infarction. Am J Prev Med. 2018;55(4):455-461. doi: https://doi.org/10.1016/j.amepre.2018.05.004.

13. Lee WH, Ong SG, Zhou Y, et al. Modeling cardiovascular risks of e-cigarettes with human-induced pluripotent stem cell-derived endothelial cells. J Am Coll Cardiol. 2019;73(21):2722-37. doi: https://doi.org/10.1016/j. jacc.2019.03.476 